Research Article

\title{
Study on Sensitivity Parameters Analysis of Grouting Reinforcement Underpassing Existing Subway Tunnel by Numerical Modeling
}

\author{
Zaiqiang $\mathrm{Hu},{ }^{1}$ Bin $\mathrm{Ma},{ }^{1}$ Xingzhou Chen $\left(\mathbb{1},{ }^{2}\right.$ and Lili Chen ${ }^{2}$ \\ ${ }^{1}$ School of Civil Engineering and Architecture, Xi'an University of Technology, Xi'an, China \\ ${ }^{2}$ School of Architecture Civil and Engineering, Xi'an University of Science and Technology, Xi'an, China \\ Correspondence should be addressed to Xingzhou Chen; 13571885799@163.com
}

Received 29 September 2020; Revised 11 December 2020; Accepted 23 January 2021; Published 3 February 2021

Academic Editor: Weerachart Tangchirapat

Copyright (C) 2021 Zaiqiang Hu et al. This is an open access article distributed under the Creative Commons Attribution License, which permits unrestricted use, distribution, and reproduction in any medium, provided the original work is properly cited.

When carrying out construction that underpasses existing subway tunnels, the surrounding rock is frequently disturbed. Therefore, it can loosen easily and become unstable, which makes its stability difficult to control. Here, we considered an existing subway tunnel in a certain subway section and used orthogonal experiments to design a simulation program as well as the UDEC (Universal Distinct Element Code) simulation software to determine the influences of four factors (i.e., grout density, grouting pressure, dynamic shear force, and viscosity) on the grouting reinforcement effect. The following results were obtained: (1) the combination of the construction method and the grouting parameters strongly influences the reinforcement effect on the surrounding rock of the tunnel. The grouting pressure is not directly proportional to the stability of the surrounding rock. The dynamic adjustment of the relationship between the grouting pressure and the grout density can effectively improve the stress state of the surrounding rock of the tunnel, control surface settlement and deformation, and reduce the section reduction rate of the tunnel. (2) The distribution of joints is closely related to the failure area and form of the surrounding rock of the tunnel. For surrounding rock with well-developed joint fissures, an excessively high grouting pressure should not be used as they are unstable. (3) The effective bearing range of grouting-reinforced surrounding rock is dependent on the pore pressure and principal stress difference. The area where the pore pressure is $70-80 \%$ of the initial grouting pressure is the effective bearing range of the grouting-reinforced surrounding rock. The stability of the surrounding rock increases with decreasing principal stress difference and increasing range. (4) The actual monitored data show that the surface settlement can be effectively reduced by handling of grouting reinforcement parameters flexibly, which can meet the control standards.

\section{Introduction}

With rapid urbanization in China, the role of subways in alleviating urban congestion and facilitating travel is becoming increasingly important. With the increase in the total mileage of subways, the issue of crossing existing subway tunnels has inevitably arisen in engineering practice. Disturbances between overlapping tunnels may cause problems such as large deformation and slow convergence of the surrounding rock around the tunnel. Therefore, studying the control of the surrounding rock when crossing existing subway tunnels is crucial for ensuring the safety of subway construction. In this regard, grouting technology can effectively improve the mechanics and water blocking performance of the surrounding rock with controllable cost. Therefore, it has been widely used as an important auxiliary method in the construction of overlapping tunnels in the Qingdao, Shenzhen, and Shenyang subways.

Many scholars in China have studied grouting technology and presented valuable research results. For example, Tai et al. combined a numerical simulation and a field measurement to study an undercut intersecting and overlapping tunnel project [1]. Duan and Li studied the reinforcement results of double-tunnel double-layer overlapping subway tunnels with advanced small pipe preinjection cement and water glass double grout [2]. Liu et al. used 
numerical simulation methods to study the effects of stress release and seepage on the tunnel structure and soil deformation during the excavation of overlapping tunnels [3]. Lin et al. used a self-built finite element model of the hardening effect to conduct numerical simulation analysis of the construction process of a double-line shield tunnel [4]. $\mathrm{Xia}$ et al. conducted optimized analysis of a grouting reinforcement test and excavation methods of a subway tunnel cross-passage [5]. Wang et al. used a numerical simulation method to investigate double grout reinforcement of waterrich and weak surrounding rock sections [6]. Zhou and Chne studied key points in the principle, design method, and construction of a split grouting for subway tunnels in soft rheological plastic silt layers [7]. Zhang et al. analyzed the distribution pattern of a grout pressure field and fracture opening based on the grout-rock coupling effect [8]. He et al. simulated the steady flow in rough fractures using triangular, sinusoidal surfaces and the typical joint roughness coefficient (JRC) profiles [9]. Wei et al. invented a new grouting material based on sulfoaluminate cement and studied its properties under a pressure circulation [10]. Liu et al. conducted a theoretical analysis of the grouting process in silty fine stratum using a sleeve valve tube and presented the concept of multiscale hierarchical digital rock mass models for describing the rock mass [11].

Related studies on crossing existing subway tunnels mainly focus on the spatial position relationship and surface settlement [12-20]. Only a few studies have investigated the influence of construction methods and grouting parameters on the stability of the surrounding rock of the tunnel when crossing existing subway tunnels. In the engineering context of an existing crossing subway tunnel, this study used the UDEC discrete element simulation analysis software to simulate the factors affecting the grouting control of surrounding rock, analyzed and compared the results with actual measurement results, and finally determined a reasonable construction method and grouting parameters.

\section{Project Overview and Reinforcement Analysis}

2.1. Project Overview. Figure 1 shows the subway tunnel section of upper and lower overlapping sections. The vertical clearance between the upper and the lower overlapping sections of subway tunnels in a city is $2 \mathrm{~m}$. The buried depth of the existing tunnel of the upper line is $\sim 10.6-16.5 \mathrm{~m}$, and that of the crossing tunnel of the lower line is $\sim 11.6-24.5 \mathrm{~m}$. Table 1 lists the strata in subway tunnel section of upper and lower overlapping sections. The lower line crosses the existing upper line subway tunnel mainly through Paleogene strata comprising silt, round gravel, and argillaceous siltstone strata with strong permeability. The upper and lower overlapped subway tunnel sections are mainly surrounded by round gravel, and the top of the tunnel is mainly surrounded by round gravel and silt. It is a slightly dense to medium-dense stratum having a poor stability, and it can be disturbed and collapse easily. The grouting reinforcement plan for crossing the existing upper line subway tunnel was as follows: 16 grouting holes were set on each ring of the tunnel, and grouting pipes were laid into the surrounding rock of the tunnel through the grouting holes for grouting reinforcement. The grout was mainly composite grout.

2.2. Grouting Reinforcement Analysis. The construction section was located in the round gravel layer. Under the action of grouting pressure, the grout filled the pores of the round gravel sand layer by expelling the free water and gas present in this layer without changing the original pore structure and volume of the rock and soil mass. The grout had the effect of filling and cementing the pores of the round gravel sand layer and compacting and consolidating the sand layer. The grout penetrated the sidewalls and filled the pore structure of the sand layer to form a vein skeleton. Finally, a grouting-reinforced round gravel sand layer was formed; it greatly improved the overall mechanical properties of the surrounding rock. The above-described process can be divided into the filling stage, cementation and compaction stage, and bearing stage, as shown in Figure 2.

2.3. Model and Scheme of Numerical Simulation. UDEC is suitable for simulating the response of discontinuous aggregates under static or dynamic load conditions [21-25]. It can be used to analyze the pore pressure, grout diffusion, and fissure expansion under different construction methods and grouting parameters during grouting construction. The Mohr-Coulomb constitutive model is adopted for the rock and soil mass, and the Bingham constitutive model is adopted for the grout diffusion flow [26]. Table 2 lists the main rock mass and joint mechanical parameters.

The model had a length and height of $30 \mathrm{~m}$ and $33 \mathrm{~m}$, respectively. Its bottom boundary was constrained vertically, and its left and right boundaries were constrained horizontally. The model consisted of 33,547 units and 4,832 blocks, as shown in Figure 3. The built-in FISH language in UDEC was used to generate random joints. Four simulation variables were considered: grout density, grouting pressure, dynamic shear force, and viscosity. Each factor was set at three levels of change. Table 3 shows the final numerical calculation scheme based on the orthogonal experiment design principle.

\section{Results}

3.1. Surface Settlement. Figure 4 shows the data obtained from the surface settlement monitoring line. Because the grouting effectively improved the mechanical properties of the surrounding rock, most measurement points subsided by 50-60 mm, and the surface settlement values were small; this was conducive to control the surface settlement. Schemes 1 , 4 , and 7 showed lower surface settlement curve fluctuations than other schemes, with settlements of 57-59 mm. Schemes 2,5 , and 8 showed a lower settlement for each measurement point on the surface, with an average value of $\sim 51 \mathrm{~mm}$; this represented a reduction of $\sim 7 \mathrm{~mm}$ (i.e., improved performance) compared with schemes 1, 4, and 7. Schemes 6 and 9 showed uplifts on the surface; in particular, scheme 9 showed a maximum uplift of $123 \mathrm{~mm}$ owing to the large 


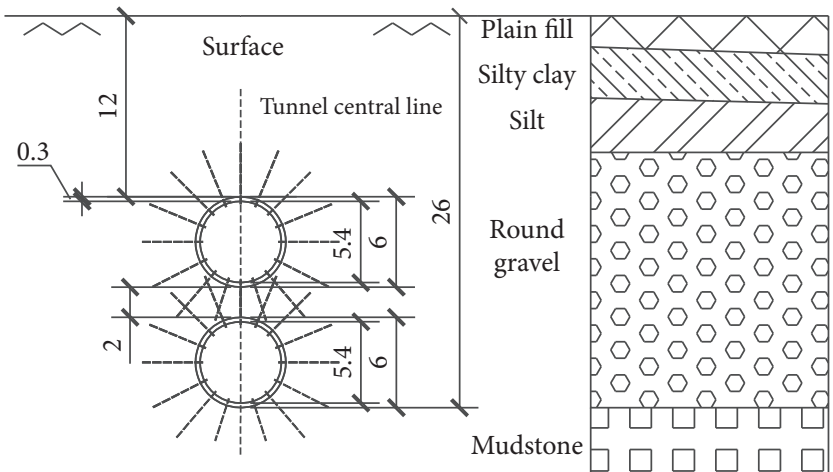

Figure 1: Subway tunnel section of upper and lower overlapping sections (unit: $\mathrm{m}$ ).

TABLE 1: Strata in subway tunnel section of upper and lower overlapping sections.

\begin{tabular}{|c|c|}
\hline Stratum & Description \\
\hline Plain fill & Gray to brownish yellow, loose to slightly dense, mainly composed of clay with gravel, uneven texture \\
\hline Silty clay & Yellow-brown, hard plastic to hard state \\
\hline Silt & Yellow, gray, slightly dense, low strength, low toughness \\
\hline $\begin{array}{l}\text { Round } \\
\text { gravel }\end{array}$ & $\begin{array}{c}\text { Gray, off-white, yellow, etc.; slightly dense to medium-dense or partially dense; mainly gravel; a small proportion of pebbles, } \\
\text { good roundness, mainly subround }\end{array}$ \\
\hline Mudstone & $\begin{array}{c}\text { Gray or blue-gray, deep diagenesis, semirock and semisoil, partially containing silty sand, not obvious bedding, smooth } \\
\text { section, extremely soft rock }\end{array}$ \\
\hline
\end{tabular}

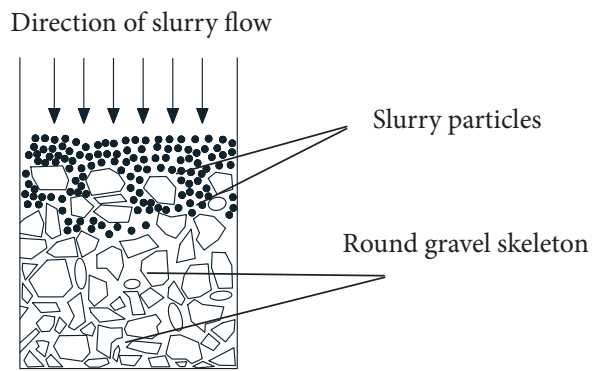

(a)

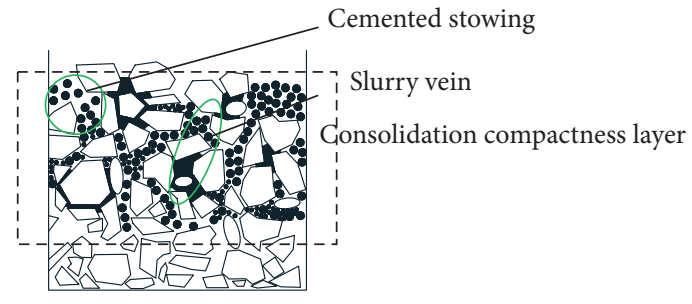

(b)

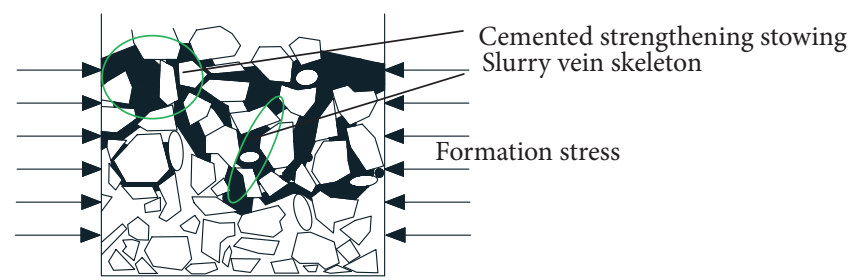

(c)

FIgURE 2: Micro process of grouting reinforcement. (a) Filling stage. (b) Cementation compaction stage. (c) Bearing stage.

TABle 2: Mechanical parameters of main rock mass and joint.

\begin{tabular}{|c|c|c|c|c|}
\hline Density $\left(\mathrm{kg} / \mathrm{m}^{3}\right)$ & Bulk modulus (GPa) & Shear modulus (MPa) & Cohesion $(\mathrm{kPa})$ & $\begin{array}{cc}\text { Internal friction } & \text { Tensile strength } \\
\text { angle }\left({ }^{\circ}\right) & (\mathrm{MPa})\end{array}$ \\
\hline 2100 & 0.138 & 59.6 & 42 & $\begin{array}{ll}30 & 1\end{array}$ \\
\hline Normal stiffness (GPa) & Tangential stiffness (GPa) & Cohesion (MPa) & Internal friction angle $\left({ }^{\circ}\right)$ & Tensile strength $(\mathrm{MPa})$ \\
\hline 0.1 & 0.1 & 0 & 25 & 0 \\
\hline
\end{tabular}




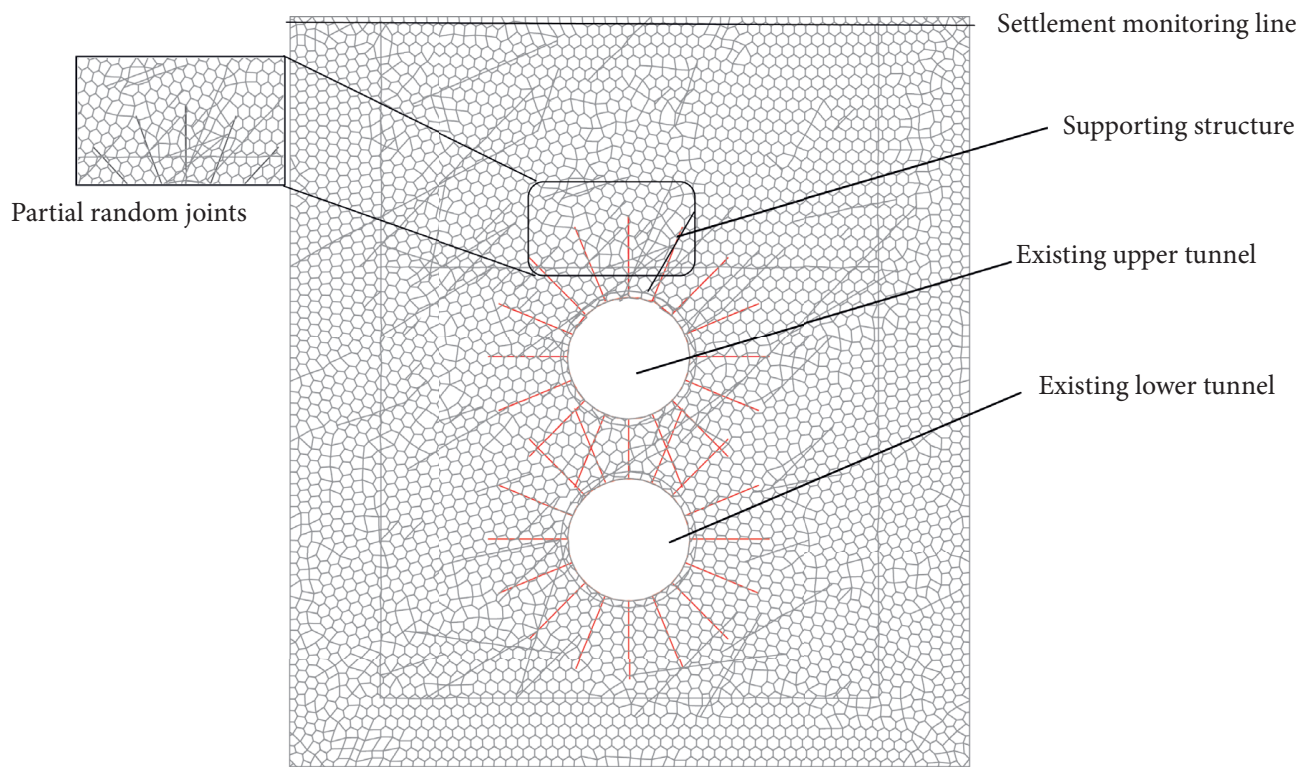

Figure 3: Tunnel model grid.

Table 3: Simulation scheme.

\begin{tabular}{lcccc}
\hline Scheme number & Density $\left(\mathrm{kN} / \mathrm{m}^{3}\right)$ & Grouting pressure $(\mathrm{MPa})$ & Dynamic shear force $(\mathrm{Pa})$ & Viscosity $(\mathrm{MPa} \cdot \mathrm{s})$ \\
\hline 1 & 15 & 0.3 & 2 & 4 \\
2 & 15 & 0.4 & 6 & 4 \\
3 & 15 & 0.5 & 4 & 5 \\
4 & 16 & 0.3 & 6 & 5 \\
5 & 16 & 0.4 & 6 & 3 \\
6 & 16 & 0.5 & 2 & 4 \\
7 & 12 & 0.3 & 4 & 5 \\
9 & 12 & 0.4 & & 3 \\
\hline
\end{tabular}

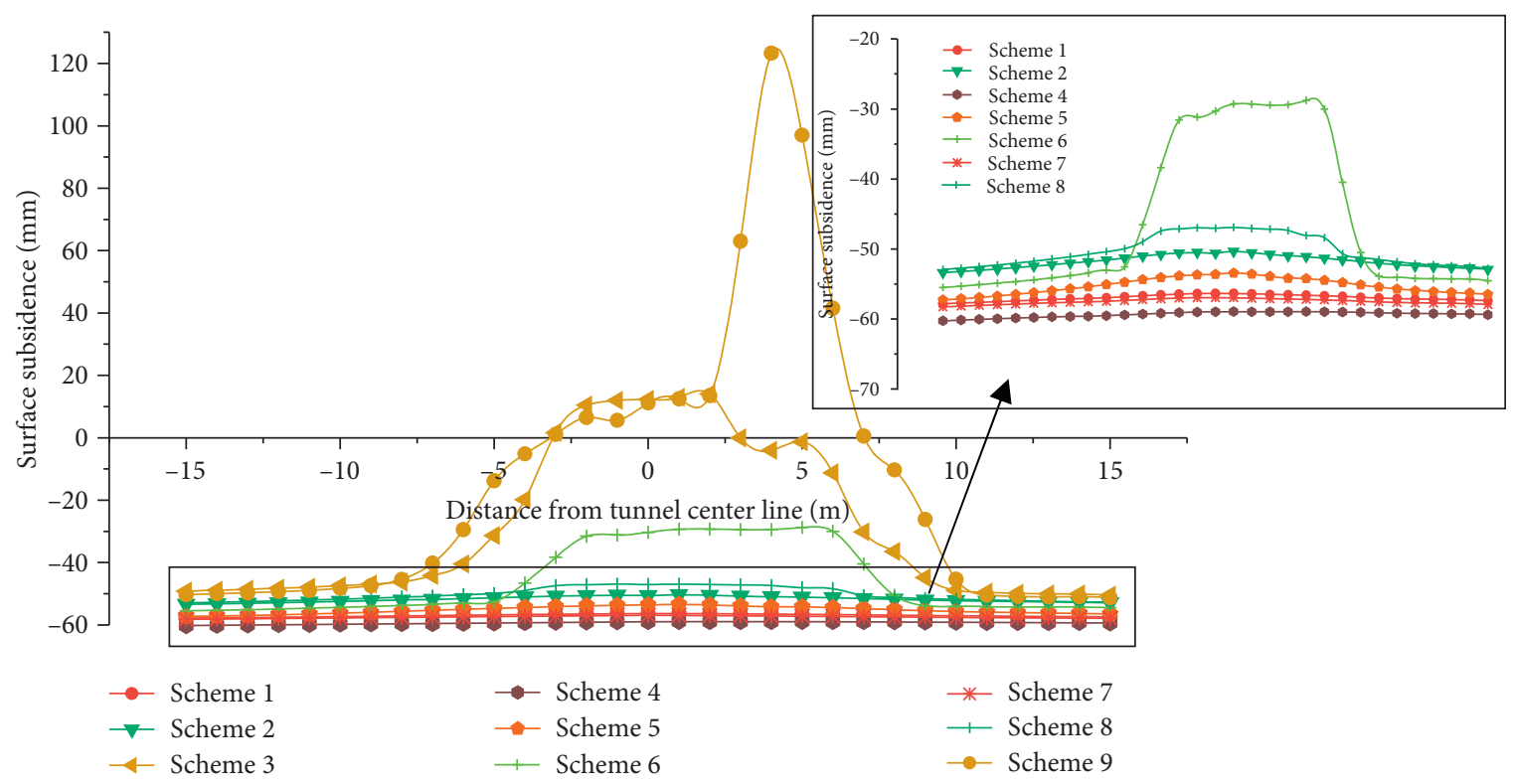

FIgURE 4: Surface settlement curve. 


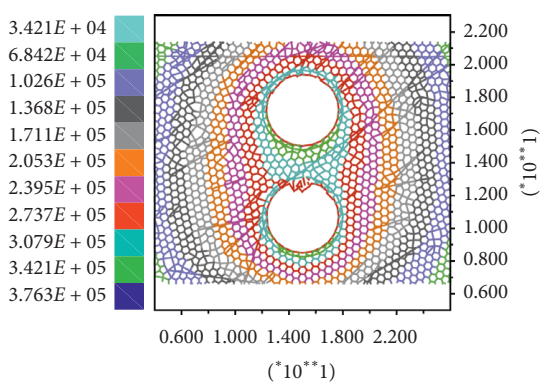

(a)

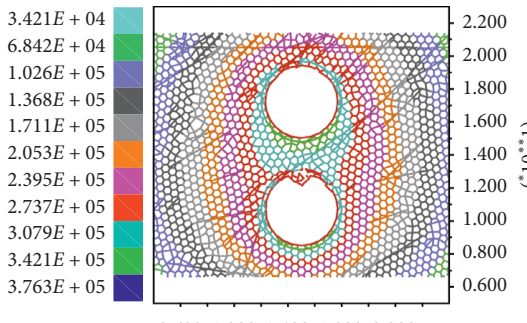

$\begin{array}{lllll}0.600 & 1.000 & 1.400 & 1.800 & 2.200\end{array}$

$\left({ }^{*} 10^{* *} 1\right)$

(d)

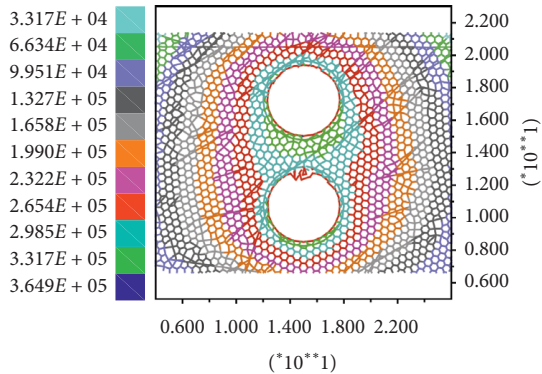

(g)

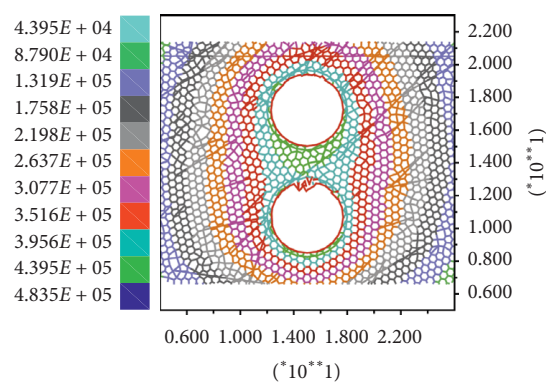

(b)
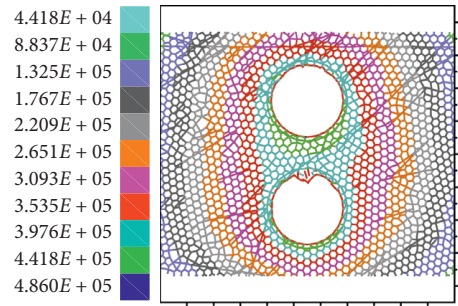

$\begin{array}{lllll}0.600 & 1.000 & 1.400 & 1.800 & 2.200\end{array}$

$\left({ }^{*} 10^{* *} 1\right)$

(e)

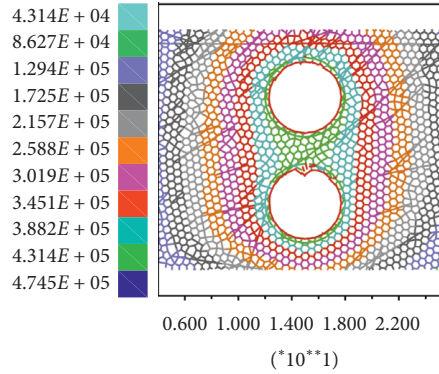

(h)

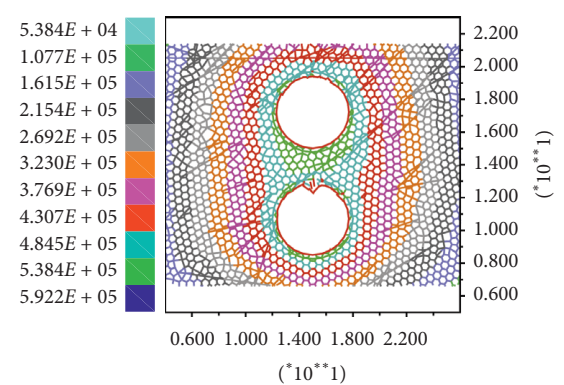

(c)

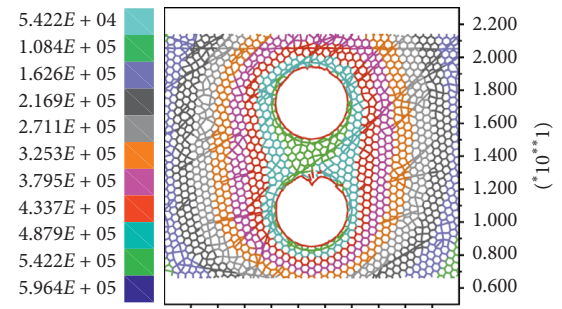

0.6001 .0001 .4001 .8002 .200

$\left({ }^{*} 10^{* *} 1\right)$

(f)

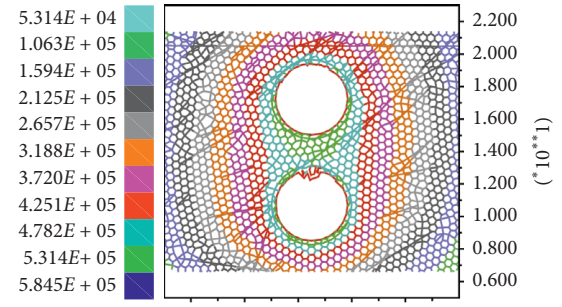

0.6001 .0001 .4001 .8002 .200

$\left({ }^{*} 10^{* *} 1\right)$

(i)

Figure 5: Pore pressure field.

uplifting force caused by the higher grouting pressure and smaller dynamic shear force. These results indicate that a higher grouting pressure is not better. Good grouting to control the settlement of the formation depends on a combination of multiple factors [21-24].

3.2. Pore Pressure. To analyze grout diffusion in the surrounding rock of the tunnel, the calculated and balanced pore pressure field was analyzed, as shown in Figure 5. The figure shows that grout diffusion was basically consistent. This figure shows that the grouting range could be divided into different zones depending on the pore pressure. Zone I (0-0.7 $\mathrm{m}$ from the tunnel wall) was mainly distributed in the middle and lower part of the tunnels on the upper and lower lines. Owing to gravity, the grout presented a concentrated trend that was 0.9-1.1 times the initial grouting pressure. Zone II (0.7-4 $\mathrm{m}$ from the tunnel wall) was $\sim 0.6-0.8$ times the initial grouting pressure; this was the main area where grouting improved the mechanical parameters of the surrounding rock of the tunnel. In zone III (4-10 $\mathrm{m}$ from the tunnel wall), the pore pressure field decreased rapidly. The pore pressure at $\sim 10 \mathrm{~m}$ away from the tunnel wall was reduced to $0.05-0.1$ times the initial grouting pressure. Zone IV had limited effect on strengthening the surrounding rock formation.

3.3. Section Reduction Rate. In mine construction, the cross section reduction rate is commonly used to characterize the overall deformation state of the tunnel. In this study, this calculation method was used to reflect the cross-sectional changes in the upper and lower tunnels after the calculation of the balance of the lower line tunnel crossing excavation.

The reduction ratio is calculated as follows:

$$
\begin{aligned}
\delta & =\frac{\Delta S}{S}, \\
\Delta S & =h B-(h-\Delta h)(B-\Delta B),
\end{aligned}
$$

where $\Delta \mathrm{h}$ is the average approaching amount of the top and bottom of the tunnel, $\triangle \mathrm{B}$ is the average approaching amount of the two sides of the tunnel, and $S$ is the initial cross-sectional area of the tunnel.

Figure 6 shows the section reduction rate. The section reduction rate of the existing tunnels on the upper line was 


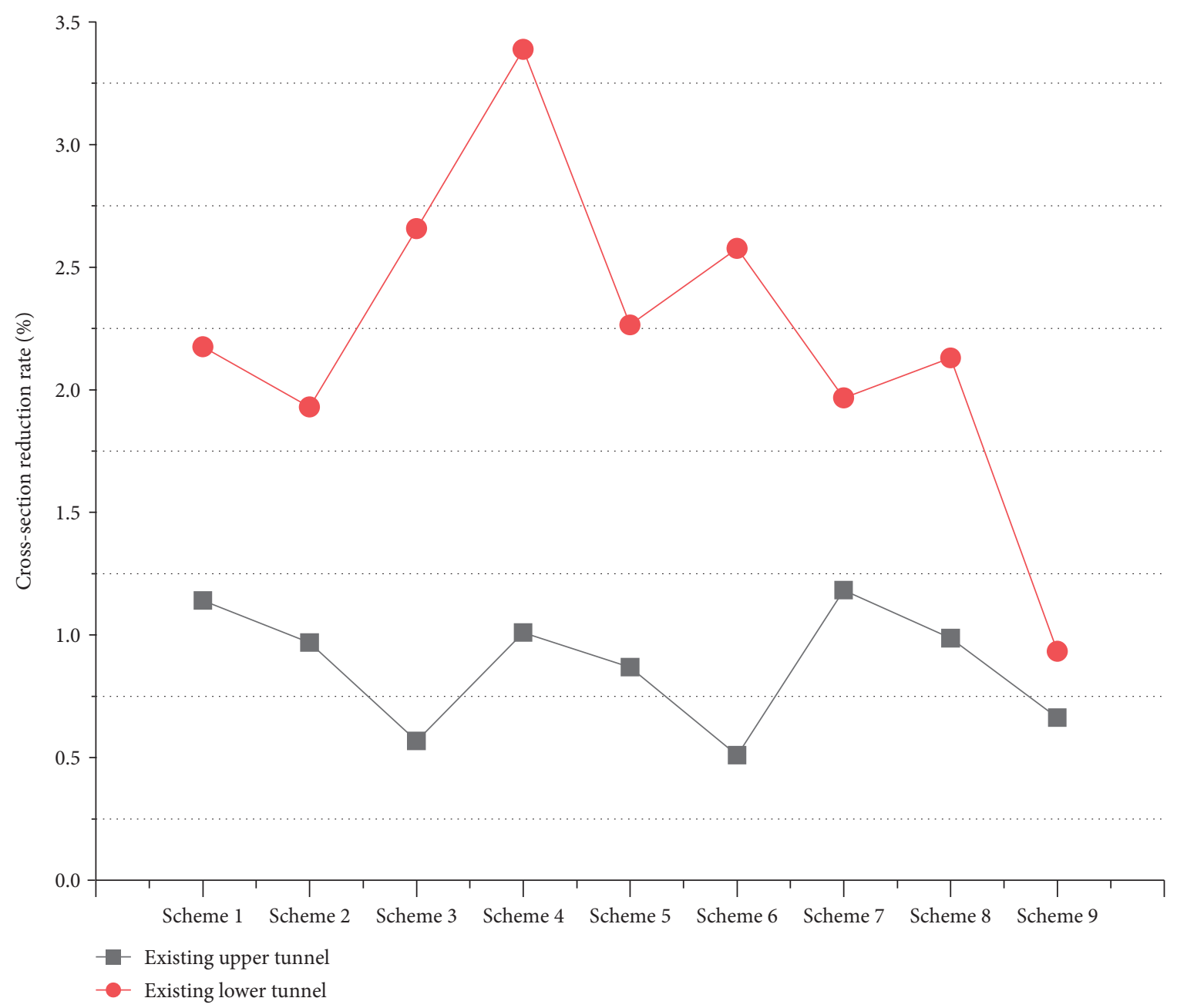

Figure 6: Section reduction rate.

$0.5 \%-1 \%$, and the average section shrinkage was $0.88 \%$. The shape of the tunnel section was basically unchanged, and the stability of the surrounding rock of the existing tunnels on the upper line had been effectively enhanced. Owing to the disturbance caused by the excavation of the existing upper tunnel, the shrinkage rate of the lower tunnel section was greater than that of the existing upper tunnel. The section shrinkage rate of the lower line crossing tunnel in scheme 4 reached $3.4 \%$, which was 3.4 times that of the existing upper tunnel. In scheme 9, the high grouting pressure, low dynamic shear force, low density, and existence of multiple joints in the surrounding rock of the existing upper tunnel created favorable conditions for the flow of grout in the surrounding rock. As a result, a noticeable uplifting force was produced in the surrounding rock after the excavation and grouting of the existing upper tunnel. The disturbance to the lower line crossing tunnel was small, and the difference in the section reduction rates of the upper and the lower line subway tunnels was the lowest among all schemes.

3.4. Failure and Fissure Distribution of Surrounding Rock. The FISH language was used to display the failure mode of the surrounding rock of the tunnel, as shown in Figure 7.
This rock was mainly damaged by stretching and shearing, and it was obviously affected by the grouting pressure. The surrounding rock of the tunnel was divided into different areas according to its failure characteristics. Area A was basically undamaged, and the surrounding rock had high stability. Area B was a key control area for dual disturbances to the stability of the surrounding rock, and it mainly showed tensile failure and supplementary shear failure and composite failure. Therefore, special measures should be taken accordingly during the construction process, especially when the grouting pressure is too high. The damage area basically penetrated the upper and lower tunnels, and therefore, it potentially posed safety risks. Area $\mathrm{C}$ showed a relatively complex damage pattern and was obviously controlled by joints. The areas around the joints showed tensile failure under low grouting pressure. High grouting pressure mainly caused shear failure and composite failure, and the failure shape took an inverted conical shape as the grouting pressure increased. In particular, when the dynamic shear force was low and the grouting pressure was high, the lifting force generated by the grouting pressure would cause the upper rock mass to move upward. Area D was the bearing area of the supporting structure. It crucially 


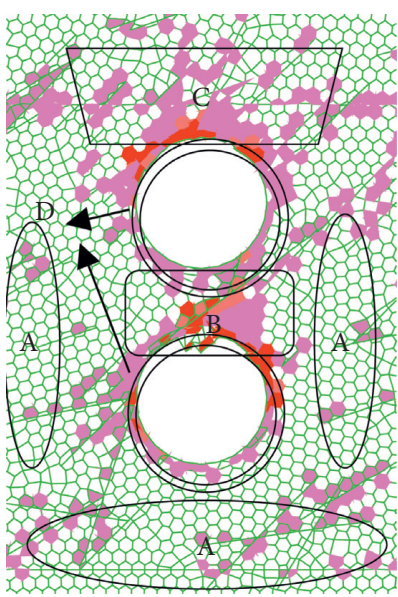

(a)

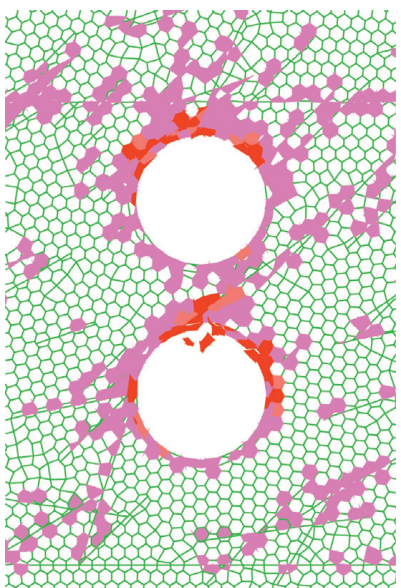

(d)

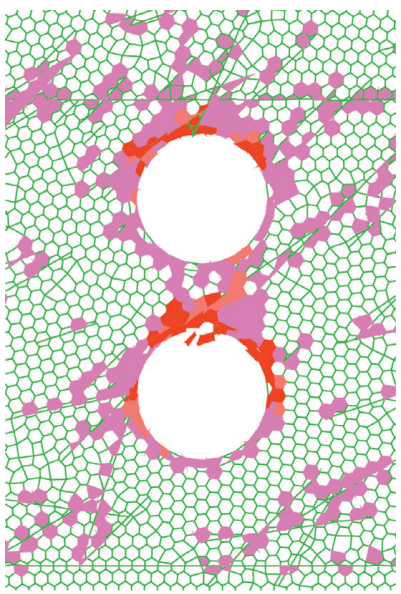

(g)

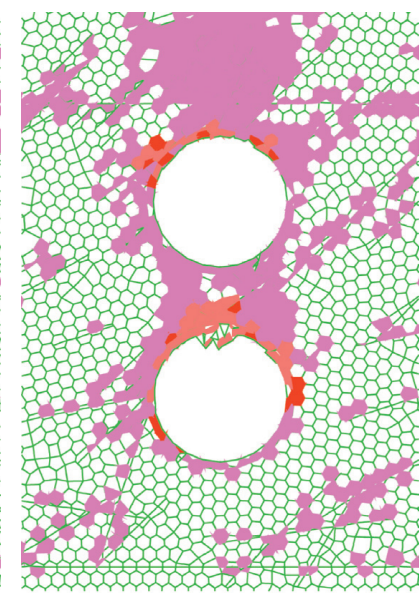

(b)

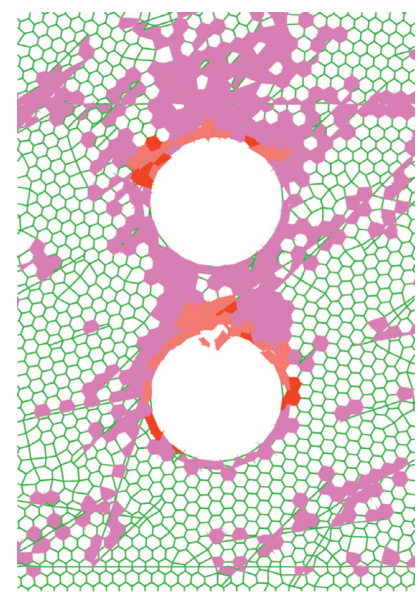

(e)

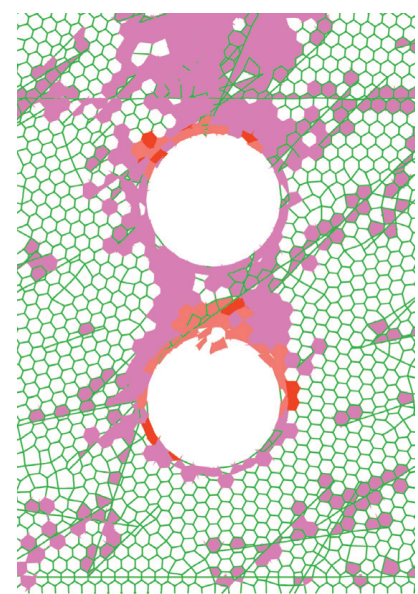

(h)

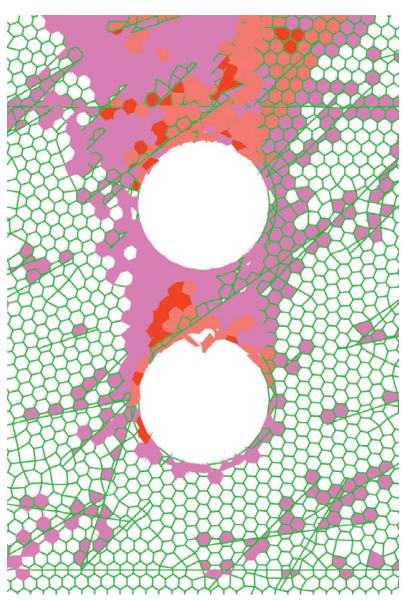

(c)

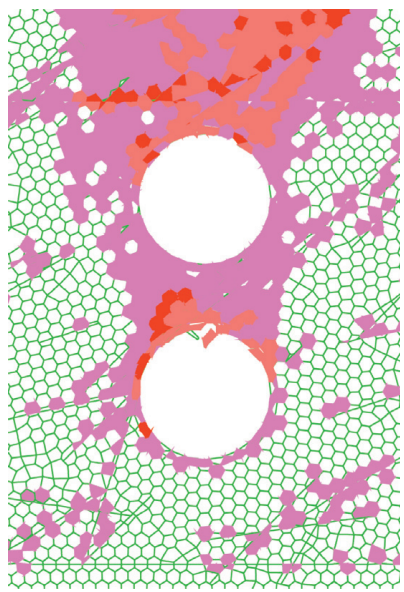

(f)

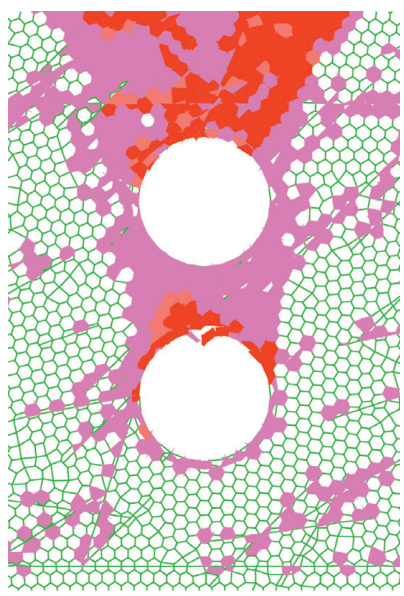

(i)

Testile failure

Shear failure

Composite Failure

FIGURE 7: Failure morphology of surrounding rock.

enabled the surrounding rock to show self-support and self-stability with tensile failure.

To show the fissure development around the tunnel more intuitively, opened and dislocated fissures were output, and the fissure number in the range shown in Figure 8 was quantitatively counted using the FISH language. In Figure 8, the tunnel outline, joint opening area, and joint dislocation area are, respectively, indicated in green, yellow, and magenta. The analysis showed that the number of fissures was $\sim 900$ in schemes 1,4 , and 7; 1,500 in schemes 2,5 , and 8 ; 


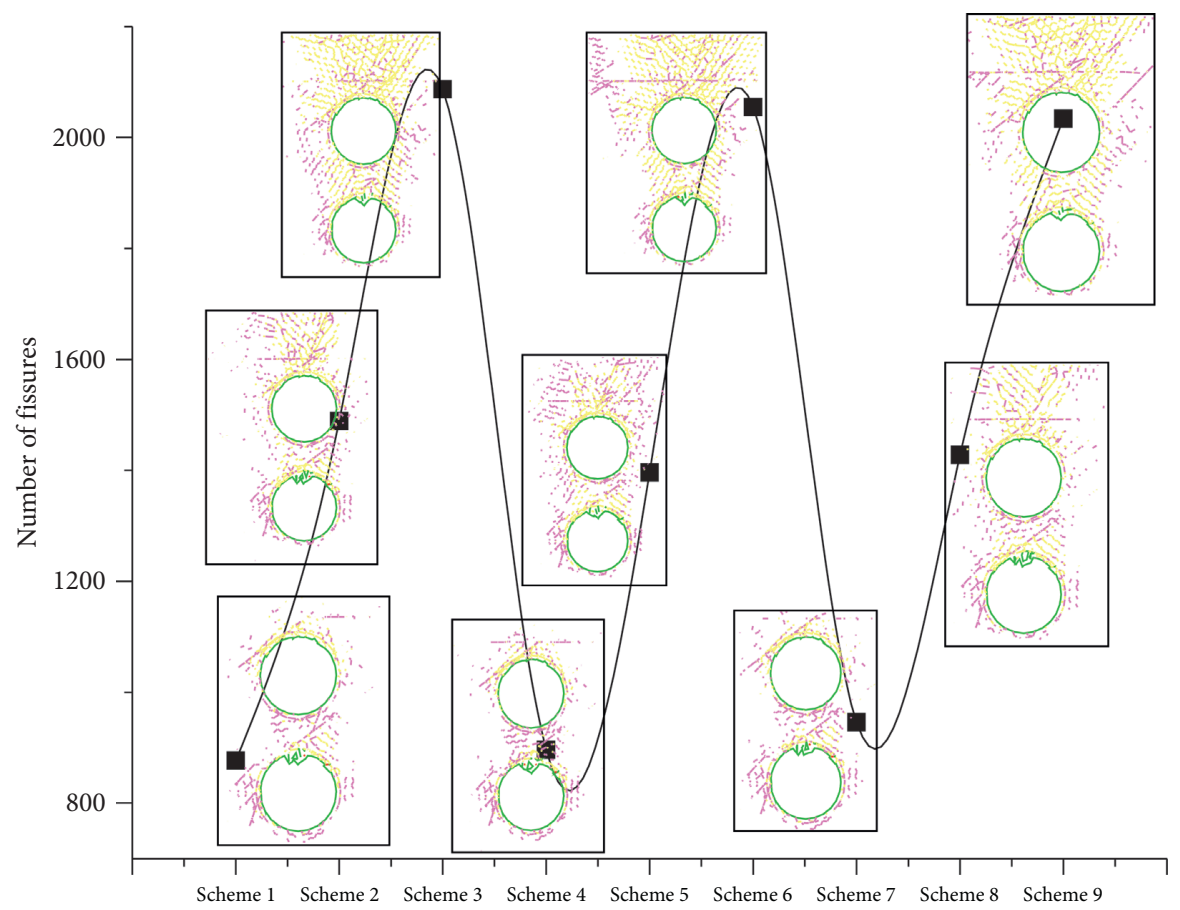

FIgURE 8: Number and distribution of fissures.

and 2,000 in schemes 3,6, and 9. Compared with the simulation scheme, the number of fissures was mainly found to be determined by the grouting pressure. As the grouting pressure increased, the number of fissures also increased. Combined with the analysis in Figure 7, basically no joint dislocation occurred in area A; however, the development range of cracks gradually increased with the grouting pressure. In area B, owing to the double disturbance in the upper and lower tunnels, secondary fissures were more developed, and joint opening and dislocation were more obvious. Area $\mathrm{C}$ had more joints in the surrounding rock of the existing upper tunnel. The fissures developed into joint-controlled-type fissures. With increasing grouting pressure, the fracturing phenomenon became more obvious and the fissure development changed from dislocation to opening. Area D was damaged by tensile failure that mainly manifested as joint dislocation. However, the number was small and the bearing effect of the support was obvious.

3.5. Principal Stress Difference. The principal stress difference reflects the elastoplasticity of the tunnel under excavation and unloading actions [27]. The purpose of the tunnel support was to reduce the stress difference and increase the strength of the surrounding rock of the tunnel. Figure 9 shows the processed image of the principal stress difference of the surrounding rock of the tunnel, where $S(\mathrm{MPa})$ is the principal stress difference.
Compared with the schemes shown in Figure 9, the regional distribution of the principal stress difference was seen to be closely related to the function of the supporting bearing area. A good supporting bearing effect could effectively reduce the area where the principal stress difference increased. The larger and smaller principal stress differences were mainly distributed in 0.01-0.15 MPa (blue area) and $0-0.01 \mathrm{MPa}$ (purple area), respectively. The principal stress difference of the existing upper tunnel was generally low, indicating that it was not significantly disturbed by the excavation of the lower line crossing tunnel. By contrast, the principal stress difference of the lower crossing tunnel was significantly larger than that of the existing upper tunnel, indicating that it was significantly disturbed by the existing upper tunnel. As the grouting pressure and dynamic shear force decreased and the viscosity increased, the principal stress difference showed an increasing trend. The principal stress difference within the $0-3 \mathrm{~m}$ range of the lower crossing tunnel was $0.15-0.35 \mathrm{MPa}$, and it gradually decreased with increasing distance from the tunnel wall. The area that was $\sim 5 \mathrm{~m}$ away had a low principal stress difference. Combined with the actual situation on-site, the grouting reinforcement effect was obviously disturbed by the existing upper tunnel. The principal stress difference in area B (key stability control area) was relatively large, being $0.35-0.6 \mathrm{MPa}$. However, when the grouting pressure was high, the grout density was low, viscosity was low, principal stress difference in area B was significantly reduced (as in scheme 9), and problems 


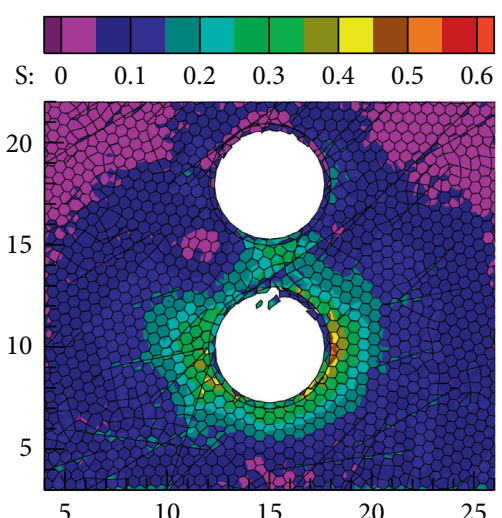

(a)

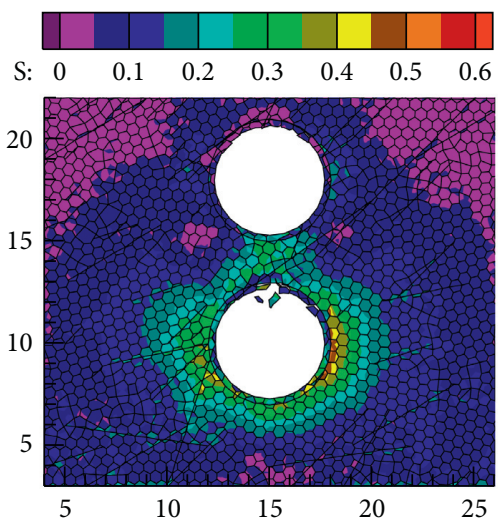

(d)

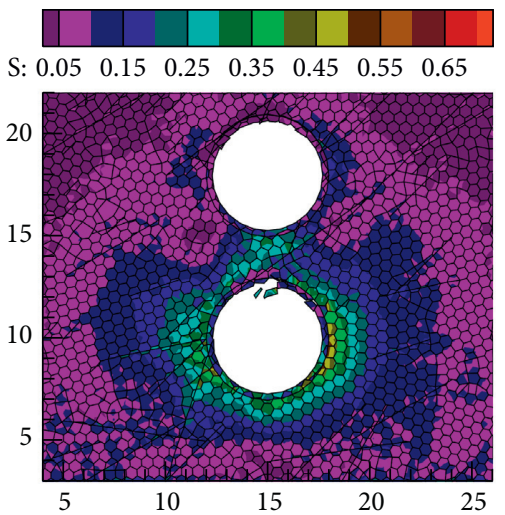

$(\mathrm{g})$

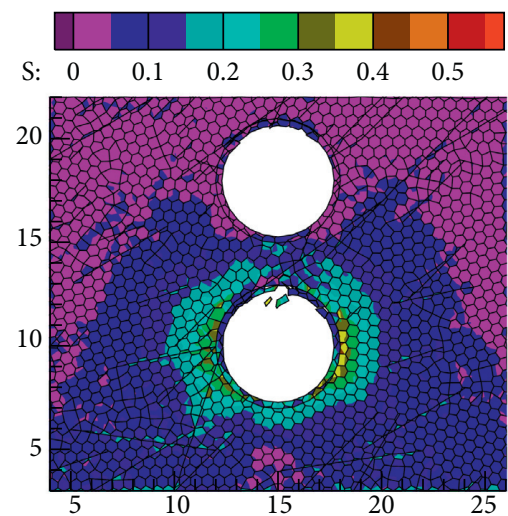

(b)

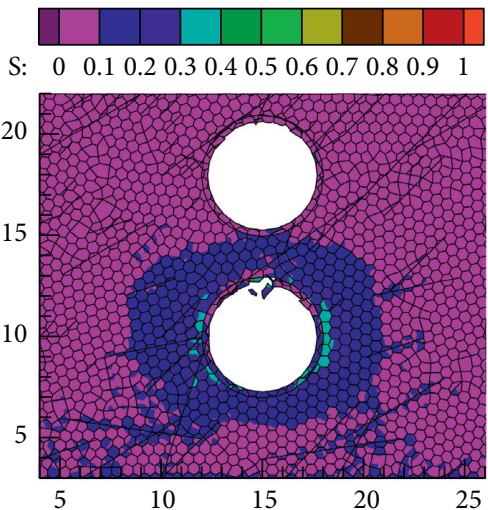

(e)
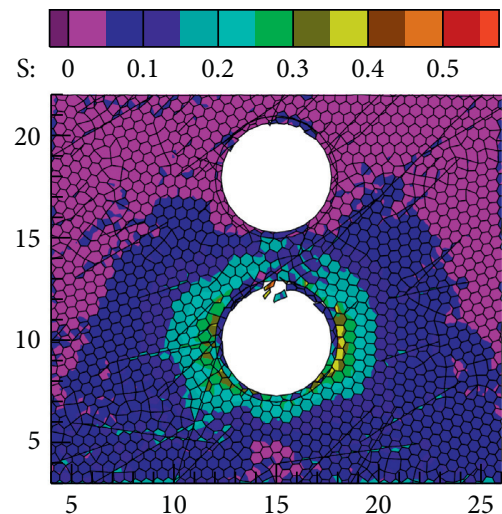

(h)

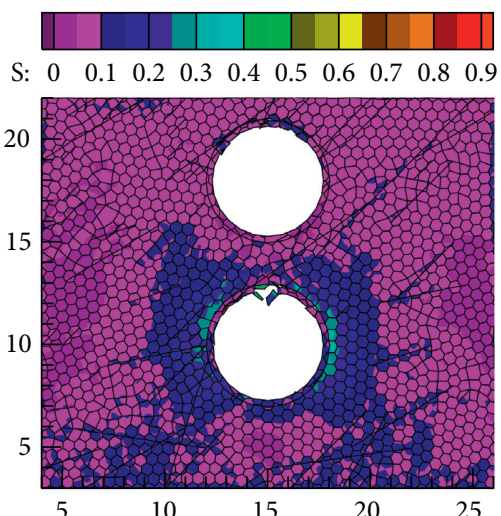

(c)

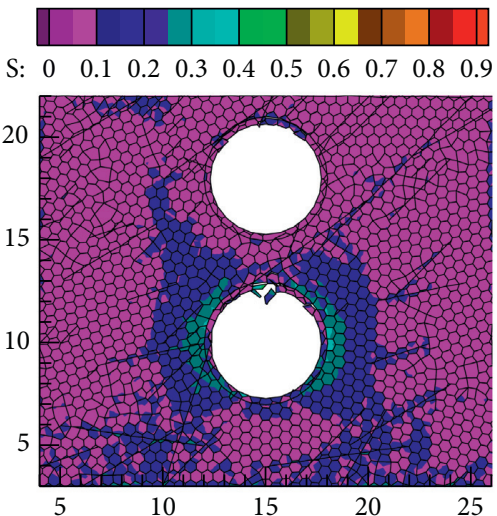

(f)
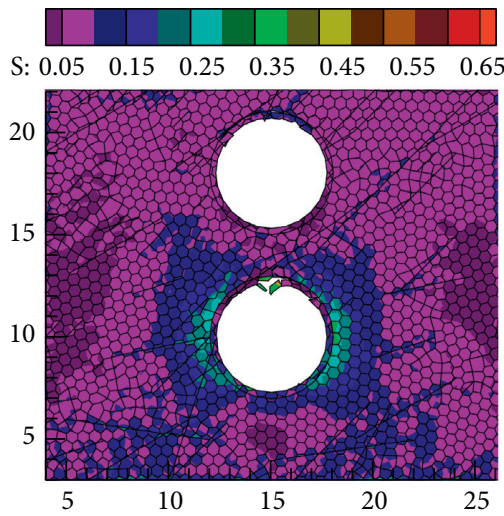

(i)

Figure 9: Principal stress difference distribution of tunnel.

such as surface uplift occurred. In schemes 1 and 4, owing to the strong dynamic shear force and high grout density, the difficulty of the grouting process increased, leading to penetration between the areas with large principal stress difference around the upper and lower tunnels. This was not conducive to enhancing the stability of the surrounding rock of the tunnel.

\section{Engineering Applications}

4.1. Scheme Analysis. Table 4 shows a comparison of the simulation of the grouting reinforcement effect for the surrounding rock after sorting the above numerical calculation results. This was used as a measurement index to conduct a range analysis of the orthogonal experiment results. Further, the optimal factor level ranking, as shown in Table 5, was obtained by sorting the influencing factors and determining the single optimal factor level and the optimal plan.

Table 5 shows that the grouting pressure had a significantly stronger influence than did other factors. Different grouting effects (measurement indicators) showed different optimal factor levels; for example, high-density grout could well control the surface settlement, low grouting pressure, 
TABLE 4: Comparison of grouting reinforcement effect in various simulation schemes.

\begin{tabular}{lccccc}
\hline $\begin{array}{l}\text { Scheme } \\
\text { number }\end{array}$ & $\begin{array}{c}\text { Average surface } \\
\text { settlement }(\mathrm{mm})\end{array}$ & $\begin{array}{c}\text { Average value of void } \\
\text { pressure in area II (MPa) }\end{array}$ & $\begin{array}{c}\text { Average section } \\
\text { reduction rate (\%) }\end{array}$ & $\begin{array}{c}\text { Number of } \\
\text { fissures }\end{array}$ & $\begin{array}{c}\text { Maximum value of principal } \\
\text { stress difference (MPa) }\end{array}$ \\
\hline 1 & 56 & 0.79 & 1.66 & 877 & 0.60 \\
2 & 51 & 0.77 & 1.45 & 1489 & 0.50 \\
3 & -- & 0.75 & 1.61 & 2087 & 0.90 \\
4 & 59 & 0.91 & 2.20 & 896 & 0.60 \\
5 & 55 & 0.77 & 1.57 & 1396 & 0.00 \\
6 & 45 & 0.76 & 1.54 & 2055 & 0.90 \\
7 & 55 & 0.77 & 1.57 & 1.56 & 1428 \\
8 & 50 & 0.75 & 0.80 & 2034 & 0.50 \\
9 & -- & 0.74 & & & 0.65 \\
\hline
\end{tabular}

TABLe 5: Optimal factor level ranking.

\begin{tabular}{|c|c|c|c|c|c|}
\hline $\begin{array}{l}\text { Assessment index } \\
\text { optimal level }\end{array}$ & $\begin{array}{l}\text { Density } \\
\left(\mathrm{kN} / \mathrm{m}^{3}\right)\end{array}$ & $\begin{array}{c}\text { Grouting } \\
\text { pressure }(\mathrm{MPa})\end{array}$ & $\begin{array}{l}\text { Dynamic shear } \\
\text { force }(\mathrm{Pa})\end{array}$ & $\begin{array}{l}\text { Viscosity } \\
\text { (MPa.s) }\end{array}$ & Ranking of effects \\
\hline $\begin{array}{l}\text { Average surface } \\
\text { settlement }\end{array}$ & 15 & 0.3 & 4 & 3 & $\begin{array}{c}\text { Grouting pressure }>\text { viscosity }>\text { dynamic shear } \\
\text { force }>\text { density }\end{array}$ \\
\hline $\begin{array}{l}\text { Average value of void } \\
\text { pressure in area II }\end{array}$ & 15 & 0.3 & 4 & 5 & $\begin{array}{c}\text { Grouting pressure }>\text { density }>\text { dynamic shear } \\
\text { force }>\text { viscosity }\end{array}$ \\
\hline $\begin{array}{l}\text { Average section } \\
\text { reduction rate }\end{array}$ & 12 & 0.3 & 2 & 6 & $\begin{array}{c}\text { Grouting } \\
\text { pressure }>\text { density }>\text { viscosity }>\text { dynamic shear } \\
\text { force }\end{array}$ \\
\hline Number of fissures & 15 & 0.5 & 6 & 4 & $\begin{array}{c}\text { Dynamic shear } \\
\text { force }>\text { density }>\text { viscosity }>\text { grouting pressure }\end{array}$ \\
\hline $\begin{array}{l}\text { Maximum value of } \\
\text { principal stress } \\
\text { difference }\end{array}$ & 12 & 0.5 & 6 & 3 & $\begin{array}{l}\text { Grouting pressure }>\text { dynamic shear } \\
\text { force }>\text { density }>\text { viscosity }\end{array}$ \\
\hline
\end{tabular}

and dynamic shear. However, low dynamic shear and high viscosity were required to control the average section reduction rate. In terms of controlling the number of fissures, excessive grouting pressure caused the number of fissures to increase, and dynamic shear had an obvious effect on controlling the number of fissures. A suitable combination of grouting pressure, grout density, dynamic shear force, and viscosity could maximize the effect of grouting to strengthen the formation. Among the various schemes, schemes 3 and 9 showed surface uplift. The mean surface settlement was assigned a null value for range analysis.

The grouting reinforcement method and grouting parameters of the underpassing existing subway tunnel section should not be considered separately. They should be considered together in a timely and reasonable manner to adjust the dynamic shear force and viscosity of the grout. Therefore, according to the actual stratum distribution, the grouting pressure should be appropriately reduced in an area where joints are densely distributed. The grout density should be appropriately reduced in an area where the ground settlement must be controlled strictly.

4.2. Field Application and Actual Measurement. In the lower tunnel, grouting holes should be constructed first at the bottom, then on the side wall, and finally at the top with intervals of 1-2 rings each time. Grouting holes on the side wall shall be in the form of "W" grouting (after completion of grouting on the left and right). The grouting pipe of drilling and injection integrated machine works on the principle of piecewise backward grouting using a piecewise step distance of $50-80 \mathrm{~cm}$. If the pressure is high, an intermittent grouting principle should be adopted, and the intermittent time is controlled in 5-10 min to ensure that the slurry is fully diffused in the formation before grouting. This is done to avoid the surface uplift, segment rupture, and slurry string caused due to excessive grouting pressure. The grouting reinforcement was mainly composite grout supplemented by ordinary cement and water glass. A $\Phi 32 \mathrm{~mm}$ TSS pipe was used as the grouting pipe. A casing drill was used to drill the hole into which the grouting pipe was inserted. The water-cement ratio of the grout ranged from $0.6: 1$ to $1: 1$. The grouting pressure was controlled to 0.3-0.6 MPa. Cement-water glass double-liquid grout was used for the interlayer of the upper and lower tunnels to compensate for the loss of the formation and to improve the self-stability of the surrounding rock. Figure 10 shows the grouting reinforcement scheme for the lower line crossing tunnel.

The tunnel construction process should be performed under the principle of the flexible handling of grouting reinforcement parameters. The surface deformation was monitored in the overlapping section where the lower tunnel crossed. The surface settlement monitoring line and measurement points were restricted by the site conditions; therefore, only two measurement lines could be set, and the measurement points were set with a distance of $\sim 5 \mathrm{~m}$. Figure 11 shows the measured surface settlement curve. The 


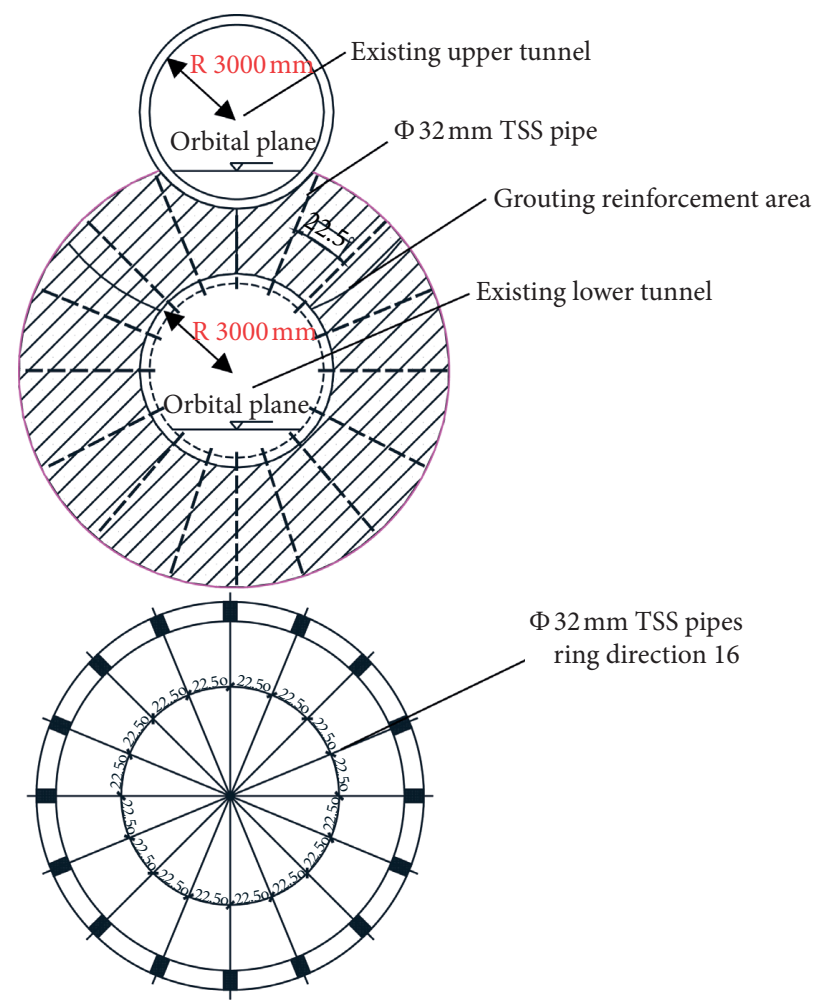

FIGURE 10: Grouting reinforcement plan for underpassing existing subway tunnel.

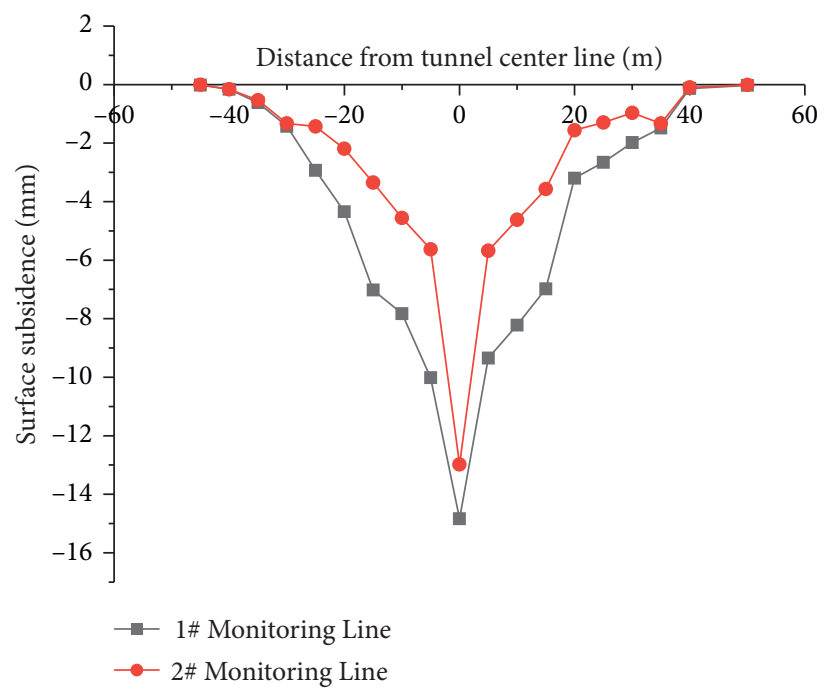

FIGURE 11: Measured surface settlement curve. 
surface settlement curve was not obvious owing to the restrictions imposed by the conditions. The maximum settlement values of the two monitoring lines were both located above the center line of the tunnel at $\sim 15 \mathrm{~mm}$ and $14 \mathrm{~mm}$, respectively; this was approximately 0.25 times the simulation value. Compared with the numerical simulation results, the measured values were all lower than the control standard range of $30 \mathrm{~mm}$. This was because the parameters were independent and many joints were randomly generated in the simulation process, thereby causing the surface settlement deformation to become too large and to not match the measured values.

\section{Conclusions}

Based on the engineering background of an existing subway tunnel section, this study used the UDEC simulation software to conduct nine sets of orthogonal simulation experiments on the main factors affecting grouting reinforcement, namely, grout density, grouting pressure, dynamic shear force, and viscosity. Random joints were added in the simulation process to restore the real formation state. The following main conclusions were obtained from this study:

(1) The use of grouting to reinforce the surrounding rock stratum of the tunnel can effectively improve the stress state of the tunnel, control the surface settlement and deformation, and reduce the section reduction rate of the tunnels.

(2) The construction method and grout parameters have an important influence on the grouting strengthening effect on the rock formation. Only increasing the grouting pressure is not adequate to enhance the stability of the surrounding rock of the tunnel. The density, dynamic shear force, and viscosity of the grout should also be considered to maximize the technical advantages afforded by grout reinforcement. An overly high grout density will increase the cost and also increase internal fissures in the surrounding rock.

(3) The distribution of joint fissures has an important influence on the failure area and failure mode of the surrounding rock of the tunnel. Joint fissures are at risk of instability under the action of a high grouting pressure. For formations with well-developed joint fissures, the grouting parameters should be kept under the principle of dynamic adjustment.

(4) The effective bearing range of the grouting-reinforced formation can be discriminated and analyzed in terms of the pore pressure value and the principal stress difference. The area where the void pressure is $\sim 80 \%$ of the initial grouting pressure is the bearing range of the grouting-reinforced stratum. The smaller the principal stress difference and the larger the area, the greater the stability of the surrounding rock. At the same time, within a certain range, a larger principal stress difference of the supporting structure indicates that the supporting structure is effective and has good bearing capacity.
(5) The measured data show that it is advisable to use grouting reinforcement construction for subway tunnel crossing the existing line, and the construction method using grouting dynamically adjusted parameters to reinforce the surrounding rock can meet the surface settlement requirements. This effectively reduces the mutual disturbance between the upper and the lower tunnels, enhances the stability of the tunnel and its surrounding rock, and ensures the safety of the upper and lower subway tunnels and the surface buildings.

\section{Data Availability}

The data used to support the findings of this study are available from the corresponding author upon request.

\section{Conflicts of Interest}

The authors declare no conflicts of interest.

\section{Acknowledgments}

This project was supported by the Joint Funds of the National Natural Science Foundation of China (Grant no. U1965107) and the National Natural Science Foundation of China (Grant no. 51979218).

\section{References}

[1] Q. M. Tai, D. L. Zhang, Q. Fang et al., "Analysis of ground surface deformation induced by excavation of crossing metro tunnels in urban underground," Chinese Journal of Rock Mechanics and Engineering, vol. 33, no. 12, pp. 2472-2480, 2014.

[2] B. Duan and L. Li, "Study of construction technology for subsurface excavation of metro tunnel group in complex environment," Chinese Journal of Rock Mechanics and Engineering, vol. 31, no. s1, pp. 2776-2782, 2012.

[3] W. Liu, X. Tang, and P. Gan, "Soil deformation induced by overlapping tunneling in water-bearing strata," Chinese Journal of Geotechnical Engineering, vol. 35, no. 6, pp. 1055-1061, 2013.

[4] Z. Lin, H. Zhu, and C. Xia, "Numerical modeling study on interaction between twin shields tunneling," Chinese Journal of Underground Space and Engineering, vol. 5, no. 1, pp. 85-89, 2009.

[5] M. Xia, W. Li, X. Feng, G. Zhu, and X. Li, "Grouting reinforcement and excavation stability on super-shallow buried and water-rich sand stratum subway transverse channel," Journal of Shandong University (Engineering Science), vol. 47, no. 2, pp. 47-54, 2017.

[6] X. Wang, T. Liu, and E. Wang, "Grouting effect on the settlement of subway tunnel construction," Chinese Journal of Geotechnical Engineering, vol. 32, no. s2, pp. 402-405, 2010.

[7] S. Zhou and J. Chne, "Hydrofracture grouting in soft flowing mucky ground for a metro tunnel," Chinese Journal of Geotechnical Engineering, vol. 24, no. 2, pp. 222-224, 2002.

[8] L. Zhang, Q. Zhang, R. Liu, and S. Li, "Grouting mechanism in fractured rock considering slurry-rock stress coupling effects," Chinese Journal of Geotechnical Engineering, vol. 40, no. 11, pp. 2003-2011, 2018. 
[9] G. He, E. Wang, and X. Liu, "Modified governing equation and numerical simulation of seepage flow in a single fracture with three-dimensional roughness," Arabian Journal of Geosciences, vol. 9, no. 1, pp. 81-100, 2016.

[10] X. Wei, X. Liu, Y. Duan, and J. Feng, "Property transformation of a modified sulfoaluminate grouting material under pressure circulation for a water-sealed underground oil cavern," Construction and Building Materials, vol. 140, pp. 210-220, 2017.

[11] X. Liu, F. Wang, J. Huang, S. Wang, Z. Zhang, and K. Nawnit, "Grout diffusion in silty fine sand stratum with high groundwater level for tunnel construction," Tunnelling and Underground Space Technology, vol. 93, Article ID 103051, 2019.

[12] Q. Zhang, C. Yang, and H. Li, "Influence of grouting on vertical deformation of underlying existing subway tunnel subjected to excavation unloading," Journal of Beijing Jiaotong University, vol. 35, no. 1, pp. 92-78, 2011.

[13] X. Ni, C. Xu, and W. Li, "Numerical simulation of grouting in micro fractured rock mass of metro tunnel considering effect of fluid-solid coupling," Tunnel Construction, vol. 38, no. 10, pp. 1667-1673, 2018.

[14] J. Huang, D. Li, and G. Xu, "Analysis of deformation regularity of stratum above overlap tunnel," Rock and Soil Mechanics, vol. 28, no. 12, pp. 2634-2638, 2007.

[15] W. Ruan, "Spreading model of grouting in rock mass fissures based in time-dependent behavior of viscosity of cement-based grouts," Chinese Journal of Rock Mechanics and Engineering, vol. 24, no. 15, pp. 2709-2714, 2005.

[16] Q. Wang, Z. Feng, and L. Wang, "Numerical analysis of grouting radius and grout quantity in fractured rock mass," Journal of China Coal Society, vol. 41, no. 10, pp. 2588-2595, 2016.

[17] X. Ji, W. Tang, W. Tan et al., "Study of key construction technologies for multiple closely spaced tunnels in an urban area," Modern Tunnelling Technology, vol. 49, no. 6, pp. 23-31, 2012.

[18] E. Soliman, H. Duddeck, and H. Ahrens, "Two- and threedimensional analysis of closely spaced double-tube tunnels," Tunnelling and Underground Space Technology, vol. 8, no. 1, pp. 13-18, 1993.

[19] G. Swoboda and A. Abu-Krisha, "Three-dimensional numerical modelling for TBM tunnelling in consolidated clay," Tunnelling and Underground Space Technology, vol. 14, no. 3, pp. 327-333, 1999.

[20] L. Liu, X. Wang, Z. Jia et al., "Method to determine reduction factor of water pressure acting on tunnel linings using water-rock independent calculation methodology," Chinese Journal of Geotechnical Engineering, vol. 35, no. 3, pp. 495-500, 2013.

[21] S. Pelizza and D. Peila, "Soil and rock reinforcements in tunneling," Tunneling and Underground Space Technology, vol. 8, no. 3, pp. 223-233, 1993.

[22] P. Qin, "Micromechanics particle flow numerical simulation on sandy soil grouting," Journal of Civil Engineering and Management, vol. 34, no. 4, pp. 30-38, 2017.

[23] L. Yang, F. Lin, and Z. Li, "Influence of grout viscosity on the grouting reinforcement effect of completely weathered granite," China Journal of Highway and Transport, vol. 31, no. 10, pp. 246-254, 2018.

[24] Y. Hao, "Determination and analysis of main parameters for cement slurry rheological characteristics," Advances in Science and Technology of Water Resources, vol. 20, no. 4, pp. 32-34, 2000 .
[25] Itasca Consulting Group Inc, UDEC (Universal Distinct Element Code) User's Manual Version 3.0[R].[sl.], Itasca Consulting Group Inc., Minneapolis, MN, USA, 2014.

[26] G. Lombadi and D. Li, The Effect of Cohesion on the Cement Grouting in Rock Mass," the Collected Papers on Modern Grouting Technology, pp. 59-75, China Water g. Power Press, Beijing, China, 1991, in Chinese.

[27] D. Chang, G. Li, and Z. Shen, "Study of bottom-hole stress field with differential pressure of 3D in-situ stress under different drilling conditions," Yantu Lixue/Rock and Soil Mechanics, vol. 32, no. 5, pp. 1546-1552, 2011. 